\title{
Using microbes as a key tool to unravel the mechanism of autophagy and the functions of the ATG proteins
}

\author{
Mario Mauthe ${ }^{1,2}$ and Fulvio Reggiori ${ }^{1,2, *}$ \\ ${ }^{1}$ Department of Cell Biology, University Medical Center Groningen, University of Groningen, A. Deusinglaan 1, 9713 AV Groningen, \\ The Netherlands. \\ ${ }^{2}$ Department of Cell Biology, University Medical Center Utrecht, Center for Molecular Medicine, Heidelberglaan 100, 3584 CX \\ Utrecht, The Netherlands. \\ * Corresponding Authors: \\ Fulvio Reggiori; E-mail: f.m.reggiori@umcg.nl
}

\begin{abstract}
The study of microbe infections has always been a very effective approach to unveil and dissect cellular pathways. Autophagy is not an exception. Although some of the breakthrough discoveries in the field were obtained using yeast, pathogens have been and still are a great tool to discover and characterize new molecular and functional aspects of autophagy. Research on pathogens has helped to acquire knowledge about selective types of autophagy and the assembly of the autophagy machinery, i.e the autophagy-related (ATG) proteins, but also about alternative cellular roles of this pathway, such as secretion. Finally, microbes have also served to discover and characterize unconventional functions of the ATG proteins, which are uncoupled from their role in autophagy. In our recent study, we have taken advantage of viruses as a screening tool to determine the extent of the unconventional functions of the ATG proteome and characterize one of them.
\end{abstract}

\footnotetext{
WHAT HAVE WE LEARNED ABOUT AUTOPHAGY BY STUDYING PATHOGEN INFECTIONS?

The hallmark of autophagy is the autophagosomes, doublemembrane vesicles that originate from cistern structures called phagophores and that eventually fuse with lysosomes, where their sequestered cargo is turned over. For a long time, autophagy has been believed to be a nonselective, bulk degradation pathway within the cell, but recent evidences highlighted that determined stimuli trigger selective types of autophagy to target specific structures for lysosomal turnover [1]. In mammalian cells, the investigation of bacterial infections has been an important source of knowledge for the mechanistic principles underlying selective types of autophagy (Fig. 1A). Selective degradation of pathogens by autophagy, also defined as xe-
}

nophagy, was initially described for the intracellular elimination of Group A Streptococcus [2]. Another extensively studied model for xenophagy is the infection of Salmonella. After escaping into the cytosol from phagosomes, Salmonella becomes rapidly ubiquitinated and is sequestered into autophagosomes. These observations have prompted several groups to investigate the proteins that are responsible to target (ubiquitinated) bacteria, but also other pathogens into autophagosomes. These so-called autophagy receptors, which include nuclear dot protein $52 \mathrm{kDa}$ (NDP52), p62 and OPTINEURIN (OPTN), have been identified and characterized by various laboratories [3-5]. Although several autophagy receptors recognize the same bacterium, their function is not redundant but rather cooperative in restricting bacterial growth. The key feature of these autophagy receptors is that they can simultaneously bind ubiquitin and microtubule-associated protein 1 light chain 3 (LC3). Thereby, they effectively mediate the sequestration of ubiquitinated bacteria into autophagosomes. These principles of xenophagy have also been shown to be valid for other selective types of autophagy, which permit the disposal of protein aggregates, mitochondria or mid body ring (Fig. 1A) [1]. A common factor that connects different selective forms of autophagy is the Tank-binding kinase 1 (TBK1). TBK1 can phosphorylate multiple autophagy receptors (e.g. OPTN, p62, NDP52) and thereby enhances their binding to LC3. In particular, phosphorylation of OPTN by TBK1 promotes selective sequestration of microbes as well as mitochondria [6]. In the context of Salmonella infection, the laboratory of Felix Randow has identified another molecule, GALECTIN8, which is involved in xenophagy [7]. This lectin does not bind directly to the invading bacteria but rather interacts with the glycans present in the lumen of host cell organelles that get exposed when microbes, such as Salmonella, disrupt the membrane of the bacterium-containing compartments. These mem-

doi: $10.15698 /$ mic2017.01.550

Received 09.11.2016, Accepted 19.12.2016, Published 30.12.2016.

Keywords: pathogens, picornavirus, unconventional function, virus, mechanisms, ATG13, FIP200. 
brane remnants are recognized by GALECTIN8, which in turn recruits NDP52 and thereby initiates autophagosome formation in close proximity of the invading bacterium [7]. In addition to GALECTIN8, GALECTIN3 also localizes to disrupted membranes during Shigella infection when the bacteria escape into the cytosol from phagosomes [8]. Interestingly, GALECTIN3 also detects membranes of damaged lysosomes and acts as a signal for autophagy-mediated turnover of these organelles (Fig. 1A) [9].

The study of microbes, in particular of bacteria, has al- so been valuable to acquire knowledge about the mechanism that leads to the assembly of the ATG machinery during selective types of autophagy (Fig. 1A). During bulk autophagy, the ATG machinery assembles by following a distinct sequential hierarchy to initiate the autophagosome formation [10]. Kageyama and colleagues have revealed that upon induction of the formation of autophagosomes that target invading Salmonella, the functional groups composing the ATG machinery act in parallel axes, rather than sequentially [11]. In particular, although LC3 recruit-

A

Lessons on autophagy from microbial infections

\begin{tabular}{|c|c|c|}
\hline Studied microbes & Discovery & $\begin{array}{l}\text { Implications in } \\
\text { uninfected cells }\end{array}$ \\
\hline $\begin{array}{l}\text { - Salmonella } \\
\text { - Shigella flexneri } \\
\text { - Group A Streptococcus }\end{array}$ & $\begin{array}{c}\text { Autophagy receptors and } \\
\text { adaptors } \\
\text { (NDP52, p62, OPTN, } \\
\text { GALECTIN3/8) }\end{array}$ & $\begin{array}{l}\text { Mechanism of disposal for } \\
\text { protein aggregates, } \\
\text { mitochondria, mid body } \\
\text { ring, } \\
\text { endosomes/lysosomes... }\end{array}$ \\
\hline - Salmonella & $\begin{array}{c}\text { ATG assembly } \\
\text { mechanism during } \\
\text { xenophagy }\end{array}$ & $\begin{array}{l}\text { Disposal of mitochondria } \\
\text { and possibly other } \\
\text { structures targeted by } \\
\text { selective autophagy }\end{array}$ \\
\hline $\begin{array}{l}\text { - Mycobacterium } \\
\text { - picornaviruses } \\
\text { - Influenza A virus (IAV) }\end{array}$ & $\begin{array}{c}\text { ATG protein-mediated } \\
\text { secretion }\end{array}$ & $\begin{array}{l}\text { Unconventional secretion of } \\
\text { cytokines, protein } \\
\text { aggregates and organelles }\end{array}$ \\
\hline
\end{tabular}

FIGURE 1: Tabular illustration resuming the studies mentioned in this commentary on microbes that have led to (A) the deciphering of autophagyrelated processes and mechanisms, and (B) the identification of unconventional functions of the ATG proteins.

\section{B}

\section{Lessons on unconventional functions of ATG proteins from microbial infections}

\begin{tabular}{|c|c|}
\hline Studied microbes & Unconventional roles \\
\hline $\begin{array}{l}\text { - Burkholderia pseudomallei } \\
\text { - Leishmania major } \\
\text { - fungi }\end{array}$ & $\begin{array}{l}\text { LC3-associated } \\
\text { phagocytosis }\end{array}$ \\
\hline $\begin{array}{l}\text { - Mouse Hepatitis virus } \\
\text { (MHV) } \\
\text { - Equine Arteritis virus (EAV) }\end{array}$ & LC3-I mediated replication \\
\hline $\begin{array}{l}\text { - Chlamydia trachomatis } \\
\text { - Brucella abortus } \\
\text { - Toxoplasma gondii } \\
\text { - Vaccinia virus (VaV) } \\
\text { - Norovirus }\end{array}$ & $\begin{array}{c}\text { Bacterial propagation, cell-to- } \\
\text { cell spread, anti-bacterial } \\
\text { defence and antiviral } \\
\text { interferon response }\end{array}$ \\
\hline $\begin{array}{l}\text { - Herpes Simplex virus } 1 \\
\text { (HSV1) } \\
\text { - Semliki Forest virus (SFV) } \\
\text { - IAV } \\
\text { - MHV } \\
\text { - VaV } \\
\text { - Encephalomyocarditis virus } \\
\text { (EMCV) }\end{array}$ & $\begin{array}{c}36 \% \text { of } A T G \text { proteins with } \\
\text { unknown unconventional } \\
\text { function }\end{array}$ \\
\hline $\begin{array}{l}\text { - EMCV } \\
\text { - Coxsackie virus B3 (CVB3) }\end{array}$ & $\begin{array}{c}\text { ATG13 and FIP200 control of } \\
\text { picornavirus infection }\end{array}$ \\
\hline
\end{tabular}


ment and lipidation in close proximity of the bacteria requires the ATG12-ATG5-ATG16 complex, this localization is independent of ATG9 or phosphatidylinositol-3-phosphate (PI3P) generation. Nonetheless, components of the LC3 conjugation system as well as ATG9 and FIP200, a subunit of the ULK kinase complex, are all required for suppression of Salmonella growth because they are all necessary for the autophagosome biogenesis. In line with these observations, Kageyama and colleagues also observed that ATG9 associates to the invading bacteria prior to LC3. This model has been strengthened by a recent study showing that the formation of an autophagosome in close proximity of Salmonella is also modulated by activated TBK1. TBK1 is recruited to the ubiquitinated bacteria by different redundant mechanisms. This event is required for the localization of WIPI2, a PI3P-binding ATG protein, to the nascent autophagosome but not for the recruitment of LC3 [12]. Similar findings were reported for the selective degradation of mitochondria where components of the ULK complex and ATG9 are recruited to the mitochondria earlier than LC3 and in a manner that does not require autophagy receptors [13]. These findings imply that the assembly mechanism of the ATG machinery (in particular LC3 recruitment) and the principles underlying autophagosome biogenesis initialization are different between selective and non-selective autophagy.

The study of bacteria and viruses has also helped in learning about alternative functions of autophagy (Fig. 1A). It has recently been shown that the release of Mycobacterium from amoebas in a non-lytic fashion is mediated by a so-called ejectosome. Although the ATG machinery is not required for the generation of the ejectosome, it is crucial to maintain plasma membrane integrity during this Mycobacterium exit from host cells [14]. Autophagy-mediated secretion is not only important for bacteria release from host cells but also for the egression of specific viruses. Influenza virus is an example of a virus where optimal cell release depends on ATG proteins. Influenza M2 protein binds LC3 and thereby directs autophagosomes to the plasma membrane where they are required for the filamentous budding and the stability of the virions [15]. Another example is the release of picornaviral particles. In addition to employ a lytic mechanism, the virions gain access to the extracellular milieu through a non-lytic release that depends on the ATG machinery and autophagosomelike vesicles [16, 17]. Importantly, autophagy-mediated secretion has now been shown to be important for the extracellular export of endogenous factors such as cytokines, protein aggregates and organelles during developmental processes [18].

\section{PATHOGEN INFECTIONS IN THE PIONEERING DISCOVERY OF UNCONVENTIONAL FUNCTIONS OF THE ATG PROTEINS}

Although ATG proteins are principally known for their role in autophagy, the study of infections has been groundbreaking in revealing the existence of a variety of so-called unconventional functions of ATG proteins (Fig. 1B), where one or more ATG proteins are required for a process distinct from autophagy [19]. The most well-known of these unconventional functions is probably the LC3-associated phagocytosis (LAP) [20]. During LAP, the single membrane of phagosomes is modified to enhance lysosomal degradation of phagocytosed material, such as bacteria. This modification is characterized by the recruitment of LC3 through its covalent conjugation to the phosphatidylethanolamine present in the phagosomal membranes and it appears to require all ATG proteins except those that are part of the ULK kinase complex. LAP is triggered by infections by a variety of pathogens, including Burkholderia pseudomallei, Leishmania major and fungi, through the stimulation of pattern recognition receptors including specific Toll-like receptors $[20,21]$. In addition to this role in innate immunity, LAP is also involved in processing and facilitating antigen loading onto major histocompatibility complex class II during infections contributing to adaptive immunity and plays a role in the clearance of dead cells by macrophages $[22,23]$.

LC3 is also essential for the replication of viruses such as the mouse hepatitis virus (MHV) [24] and equine arteritis virus (EAV) [25]. MHV and EAV induce the formation double-membrane vesicles (DMVs) in host cells, which act as replicative platforms. DMVs were initially believed to be autophagosomes because of their double-membrane morphology. However, it has been shown that these structures are still formed in absence of ATG5 and ATG7 even if they are positive for LC3 [26]. A study from our laboratory [24] revealed that in agreement with these observations, nonlipidated LC3 localizes to DMVs and that virus replication is inhibited by LC3 depletion. Interestingly, we also showed that MHV-induced DMVs are derived from EDEMosomes, endoplasmic reticulum-derived vesicles required for the regulated removal of two factors involved in the ER quality control, i.e. EDEM1 and OS-9, which are also positive for non-lipidated LC3.

A variety of other investigations about Chlamydi trachomatis, Brucella abortus, Toxoplasma gondii, vaccinia virus or norovirus have revealed additional unconventional functions of other ATG proteins in bacterial propagation, cell-to-cell spread, bacterial defense or antiviral interferon response [19].

\section{A VIRUS-BASED SCREENING APPROACH TO IDENTIFY UNCONVENTIONAL FUNCTIONS OF ATG PROTEINS}

In one of our recent studies [27], we decided to exploit viral infections to identify novel unconventional functions of the ATG proteins. We performed an ATG proteomespecific siRNA screen and used the replication from 6 different viruses (herpes simplex virus 1 , semliki forest virus, influenza $A$ virus, mouse hepatitis virus, vaccinia virus and encephalomyocarditis virus) expressing luciferase as a read-out tool to score for the involvement of one or more ATG proteins in viral replication. Importantly, our siRNA library also took in consideration the redundancy of specific ATG genes by combining the siRNA that targeted them. 
Furthermore, we performed the screen in 2 different cell lines to avoid cell type-specific effects.

Overall, we found that $36 \%$ of the ATG proteins have a cell line-independent function in viral replication that is not connected to their role in autophagy (Fig. 1B). This number is even higher when cell type-specific events are taken in consideration. For the tested viruses, we did not find any ATG gene that is altering replication of all examined viruses and we did not observe autophagy being required in a cell line-independent manner for any of them.

To validate the outcome of the screen, we investigated in more detail two ATG proteins that are part of the ULK complex, ATG13 and FIP200, in the context of encephalomyocarditis virus (EMCV) infection. Depletion of ATG13 and FIP200 led to an increase in EMCV replication in the screen, whereas the other members of the ULK complex did not. In the follow-up experiments we could show that ATG13 and FIP200 are inhibiting the replication not only of EMCV, but also of other members of the picornavirus family, i.e. coxsackie virus B3 and A21, and enterovirus 71. Although the precise unconventional role of ATG13 and FIP200 in picornaviral infection remains to be elucidated, we showed that these two proteins suppress picornavirus infection by interfering with their replication and not by impairing the cell entry level (Fig. 1B).

Altogether, our study is another example within many showing how microbes can be very useful biological tools.
It also confirms that they can be utilized for the identification of novel functions of the ATG proteins.

\section{ACKNOWLEDGEMENTS}

We thank Rubén Gómez-Sánchez and Idil Orhon for the critical reading of the manuscript. F.R. is supported by ALW Open Program (822.02.014), DFG-NWO cooperation (DN82-303), SNF Sinergia (CRSII3_154421) and ZonMW $\mathrm{VICl}(016.130 .606)$ grants.

\section{CONFLICT OF INTEREST}

The authors declare no conflict of interest.

\section{COPYRIGHT}

(C) 2016 Mauthe and Reggiori. This is an open-access article released under the terms of the Creative Commons Attribution (CC BY) license, which allows the unrestricted use, distribution, and reproduction in any medium, provided the original author and source are acknowledged.

Please cite this article as: Mario Mauthe and Fulvio Reggiori (2016). Using microbes as a key tool to unravel the mechanism of autophagy and the functions of the ATG proteins. Microbial Cell 4(1): 1-5. doi: 10.15698/mic2017.01.550

8. Paz I, Sachse M, Dupont N, Mounier J, Cederfur C, Enninga J, Leffler H, Poirier F, Prevost MC, Lafont F, Sansonetti P (2010). Galectin-3, a marker for vacuole lysis by invasive pathogens. Cell Microbiol 12(4): 530-544.

9. Maejima I, Takahashi A, Omori H, Kimura T, Takabatake $Y$, Saitoh T, Yamamoto A, Hamasaki M, Noda T, Isaka Y, Yoshimori T (2013). Autophagy sequesters damaged lysosomes to control lysosomal biogenesis and kidney injury. EMBO J 32(17): 2336-2347.

10. Suzuki K, Kubota Y, Sekito T, Ohsumi Y (2007). Hierarchy of Atg proteins in pre-autophagosomal structure organization. Genes Cells 12(2): 209-218.

11. Kageyama S, Omori H, Saitoh T, Sone T, Guan JL, Akira S, Imamoto F, Noda T, Yoshimori T (2011). The LC3 recruitment mechanism is separate from Atg9L1-dependent membrane formation in the autophagic response against Salmonella. Mol Biol Cell 22(13): 22902300.

12. Thurston $T L$, Boyle $K B$, Allen $M$, Ravenhill BJ, Karpiyevich $M$, Bloor S, Kaul A, Noad J, Foeglein A, Matthews SA, Komander D, Bycroft M, Randow F (2016). Recruitment of TBK1 to cytosol-invading Salmonella induces WIPI2-dependent antibacterial autophagy. EMBO J 35(16): 1779-1792.

13. Itakura E, Kishi-Itakura C, Koyama-Honda I, Mizushima N (2012). Structures containing Atg9A and the ULK1 complex independently target depolarized mitochondria at initial stages of Parkin-mediated mitophagy. J Cell Sci 125(Pt 6): 1488-1499. 
14. Gerstenmaier L, Pilla R, Herrmann L, Herrmann H, Prado M, Villafano GJ, Kolonko M, Reimer R, Soldati T, King JS, Hagedorn M (2015). The autophagic machinery ensures nonlytic transmission of mycobacteria. Proc Natl Acad Sci USA 112(7): E687-692.

15. Beale R, Wise $H$, Stuart A, Ravenhill BJ, Digard P, Randow F (2014). $A$ LC3-interacting motif in the influenza $A$ virus $M 2$ protein is required to subvert autophagy and maintain virion stability. Cell Host Microbe 15(2): 239-247.

16. Bird SW, Maynard ND, Covert MW, Kirkegaard K (2014). Nonlytic viral spread enhanced by autophagy components. Proc Natl Acad Sci USA 111(36): 13081-13086.

17. Robinson SM, Tsueng G, Sin J, Mangale V, Rahawi S, Mclntyre LL, Williams W, Kha N, Cruz C, Hancock BM, Nguyen DP, Sayen MR, Hilton BJ, Doran KS, Segall AM, Wolkowicz R, Cornell CT, Whitton JL, Gottlieb RA, Feuer $R$ (2014). Coxsackievirus $B$ exits the host cell in shed microvesicles displaying autophagosomal markers. PLoS Pathog 10(4): e1004045.

18. Ponpuak M, Mandell MA, Kimura T, Chauhan S, Cleyrat C, Deretic V (2015). Secretory autophagy. Curr Opin Cell Biol 35:106-116.

19. Bestebroer J, V'Kovski P, Mauthe M, Reggiori F (2013). Hidden behind autophagy: the unconventional roles of ATG proteins. Traffic 14(10): 1029-1041.

20. Lai SC, Devenish RJ (2012). LC3-Associated Phagocytosis (LAP): Connections with Host Autophagy. Cells 1(3): 396-408.

21. Sprenkeler EG, Gresnigt MS, van de Veerdonk FL (2016). LC3associated phagocytosis: a crucial mechanism for antifungal host defence against Aspergillus fumigatus. Cell Microbiol 18(9): 12081216.
22. Green DR, Oguin TH, Martinez J (2016). The clearance of dying cells: table for two. Cell Death Differ 23(6): 915-926.

23. Shibutani ST, Saitoh T, Nowag H, Munz C, Yoshimori T (2015). Autophagy and autophagy-related proteins in the immune system. Nature Immunology 16(10): 1014-1024.

24. Reggiori F, Monastyrska I, Verheije MH, Cali T, Ulasli M, Bianchi S, Bernasconi R, de Haan CAM, Molinari M (2010). Coronaviruses Hijack the LC3-I-Positive EDEMosomes, ER-Derived Vesicles Exporting ShortLived ERAD Regulators, for Replication. Cell Host \& Microbe 7(6): 500508.

25. Monastyrska I, Ulasli M, Rottier PJM, Guan JL, Reggiori F, de Haan CAM (2013). An autophagy-independent role for LC3 in equine arteritis virus replication. Autophagy 9(2): 164-174.

26. Reggiori F, de Haan CAM, Molinari M (2011). Unconventional Use of LC3 by Coronaviruses through the Alleged Subversion of the ERAD Tuning Pathway. Viruses-Basel 3(9): 1610-1623.

27. Mauthe $M$, Langereis $M$, Jung J, Zhou $X$, Jones $A$, Omta $W$, Tooze SA, Stork B, Paludan SR, Ahola T, Egan D, Behrends C, Mokry M, de Haan C, van Kuppeveld F, Reggiori F (2016). An siRNA screen for ATG protein depletion reveals the extent of the unconventional functions of the autophagy proteome in virus replication. J Cell Biol 214(5): 619635. 